\title{
Research of Power Loop Layout and Parasitic Inductance in GaN Transistor Implementation
}

Sun, Bainan; Jørgensen, Kasper Lüthje; Zhang, Zhe; Andersen, Michael A. E.

Published in:

IEEE Transactions on Industry Applications

Link to article, DOI:

10.1109/TIA.2020.3048641

Publication date:

2021

Document Version

Peer reviewed version

Link back to DTU Orbit

Citation $(A P A)$ :

Sun, B., Jørgensen, K. L., Zhang, Z., \& Andersen, M. A. E. (2021). Research of Power Loop Layout and

Parasitic Inductance in GaN Transistor Implementation. IEEE Transactions on Industry Applications, 57(2), 1677 - 1687. https://doi.org/10.1109/TIA.2020.3048641

\section{General rights}

Copyright and moral rights for the publications made accessible in the public portal are retained by the authors and/or other copyright owners and it is a condition of accessing publications that users recognise and abide by the legal requirements associated with these rights.

- Users may download and print one copy of any publication from the public portal for the purpose of private study or research.

- You may not further distribute the material or use it for any profit-making activity or commercial gain

- You may freely distribute the URL identifying the publication in the public portal 


\title{
Research of Power Loop Layout and Parasitic Inductance in GaN Transistor Implementation
}

\author{
Bainan Sun, Student Member, IEEE, Kasper Lüthje Jørgensen, Student Member, IEEE, \\ Zhe Zhang, Senior Member, IEEE and Michael A.E. Andersen, Member, IEEE.
}

\begin{abstract}
Power loop is critical in the PCB layout consideration. Especially for high frequency GaN transistor applications, low inductance power loop design is needed to guarantee the switching reliability and the operation efficiency. Finite element analysis (FEA) is generally used in the power loop inductance quantification, which is time consuming and impractical for parameters sweep. In this paper, a numerical equation for power loop inductance estimation is given based on the novel loop inductance model. The power loop inductance can be estimated in a fast approximation approach. A minimal layout method is proposed to reduce the power loop inductance for the GaN transistor application. The impact of power loop inductance is discussed over the two operation modes of the synchronous buck converter. A modular buck converter prototype is designed to demonstrate the effectiveness of the given numerical equation and validate the lower power loop inductance by the proposed layout.
\end{abstract}

\section{INTRODUCTION}

G AN transistor has been introduced as a promising solution for the high frequency high power density converter design [1], [2]. High frequency switching largely shrinks the volume of the converter passive components [3]. Meanwhile, $\mathrm{GaN}$ transistor application introduces challenges in the PCB layout [4]. Parasitic inductance from the PCB tracks leads to transistor gate-source and drain-source voltage ringing during the switching transients. Compared with Silicone and Silicone Carbide $(\mathrm{SiC})$ transistors, $\mathrm{GaN}$ transistors are lack of avalanche breakdown, which are thus more vulnerable to the voltage overshoot for its limited drain-source voltage rating and gate voltage tolerance [5]. As a result, PCB layout optimization is critical for high frequency $\mathrm{GaN}$ transistors application.

Gate loop and power loop are the two critical loops considered in the PCB layout optimization [6]. In both optimization processes, minimization of the parasitic inductance is the major goal. For the gate loop, the parasitic inductance results in gate over-voltage during the turn-on transient and unintentional triggered-on during the turn-off transient [7], [8]. Slew rate control and negative gate voltage are applied respectively to mitigate the influence of the gate loop inductance [9]-[12]. For the power loop, the parasitic inductance is resonant with the transistor output capacitance, which leads to the drain-source voltage ringing. Extra power loss is introduced during the switching transient and the transistor can be damaged because of the over-voltage switching. Parasitic inductance of the $\mathrm{GaN}$ transistor power loop is majorly contributed by the PCB tracks, which is solely depending on layout method in the design stage. As a result, parasitic inductance quantification and

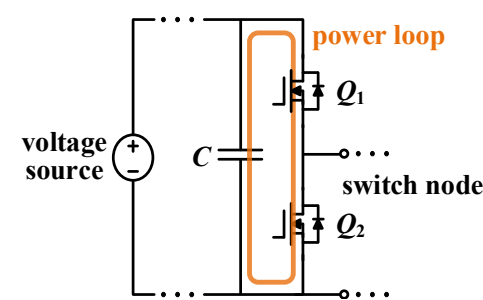

Fig. 1. Power loop in totem pole topology.

layout optimization of the transistor power loop is important in the $\mathrm{GaN}$ based converter design.

Power loop in totem pole bridge is defined as the conduction path within two transistors and paralleled decoupling capacitors as shown in Fig. 1. Totem pole bridge is the basic composing unit of voltage source converters, which can be found in single/three phase inverter, full bridge converter, dual active bridge converter and etc. Minimization of power loop inductance is the major concern in applying totem pole bridge to all different voltage source converters. Several low inductance power loop layouts have been discussed in the prior-art research. Although these results vary in the transistor implementation, integration type (discrete device or power module) and converter topology, their optimization methods for the power loop layout can be classified into two major categories: length minimization [13]-[15] and magnetic flux cancellation [16]-[20]. Effectiveness of the prior-art layout methods is generally validated either by the FEA simulation results or by the percentage overshoot measured from the drain-source voltage. A general design methodology of the low loop inductance layout is yet absent. This is mainly resulted from the lack of a general power loop inductance model and the lack of numerical equation for quantitative evaluation. One classical equation for the PCB inductance estimation is given as

$$
L_{p c b}=\mu_{0} \frac{h}{w} l,
$$

where $\mu_{0}$ is the vacuum permeability, $h$ is the distance between two PCB tracks, $w$ is the width and $l$ is the length of the PCB track.

The classical equation is derived based on the Maxwell equation, and simplified based on the assumption of uniform $H$ field between the PCB tracks and evenly distributed current flow within the conductor cross-section. In the case of high frequency power loop oscillation, both assumptions cannot be established because of the skin effect. The classical 
equation can lead to considerate estimation error compared with the FEA results. The $H$ field distribution between PCB tracks is solved in [21] based on the premise of uniform current distribution within the conductor. However, the nonuniform current distribution during high frequency oscillation is still the insurmountable barrier in power loop inductance quantification. Furthermore, the numerical equation for PCB parasitic inductance in the prior-art research is given based on the geometry of two infinite-long paralleled conductors, which should be defined as partial inductance according to the concept first proposed in [22]. Practical numerical equation for the loop inductance estimation is absent in the prior-art research.

Modeling and quantification of the GaN transistor power loop inductance is thoroughly discussed in this paper, which can be beneficial for the design of high frequency GaN based power converters. New contributions introduced in this paper include:

- A novel analytical method for power loop inductance modeling is illustrated.

- A numerical equation is given for GaN transistor power loop inductance estimation.

- A minimal layout method is proposed for power loop inductance minimization.

This paper is organized as follows: Section II introduces the modeling and quantification process of the power loop inductance. The proposed minimal layout method is explained and compared with two conventional methods in section III. Experimental results are given in section IV to validate accuracy of the proposed numerical equation and low inductance design of the proposed minimal layout. Section V concludes the paper.

\section{Power Loop Inductance}

\section{A. Modeling of the Power Loop Inductance}

Critical parasitic parameters within the power loop include the transistor output capacitance and the parasitic inductance of PCB tracks. High frequency ringing within the power loop is resulted from the oscillation between these two parasitic components. Modeling of parasitic capacitance is intuitive as the transistor inherent characteristic. However, there's a lack of generalized power loop inductance model, with modeling

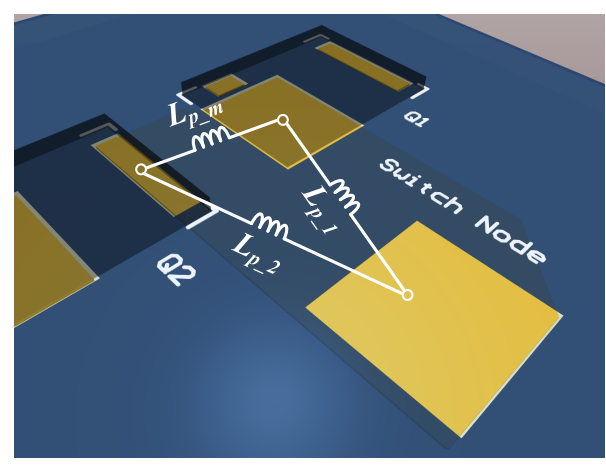

Fig. 2. Parasitic inductance of the switch node in delta connection.

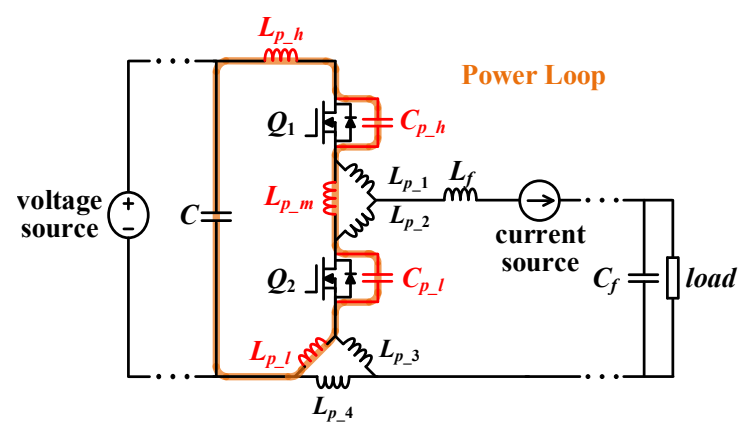

(a) Stage 1: Analytical Model.

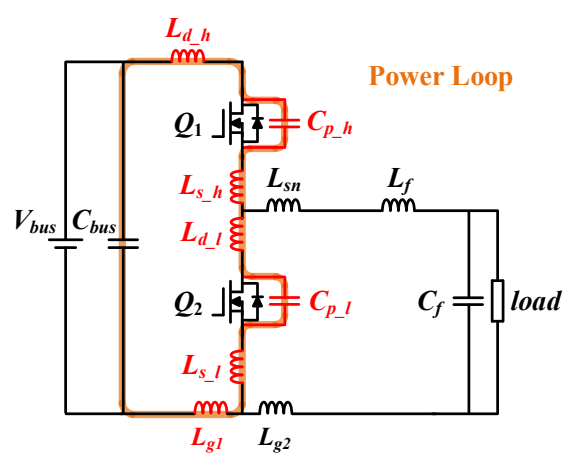

(b) Stage 2: Complete parasitic model.

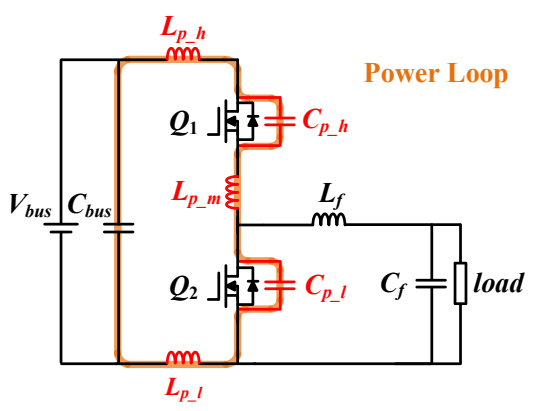

(c) Stage 3: Simplified lump inductance model.

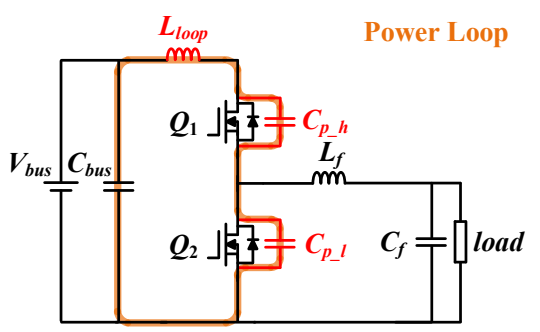

(d) Stage 4: Simplified loop inductance model.

Fig. 3. Power loop parasitic model derivation.

method varies between different prior-art researches [7], [16], [23]. The following section will illustrate the derivation of power loop inductance model in details as four stages.

1) Stage 1: Analytical model.

Difficulty and discrepancy of the parasitic inductance modeling lies in the treatment of joint node. For instance, the joint node shown in Fig. 2, which is generally known as switch node, is one single piece of copper connected between the two transistors and the rear stage circuit. Three different inductance values can be defined for this joint node according to the three difference current conduction paths. Accordingly in the 
analytical model, parasitic inductance of the switch node and the ground node is each configured as three parasitic inductors in delta connection. The analytical model is explained in the general voltage source totem pole converter, as shown in Fig. 3(a). Critical parasitic inductance in the analytical model include $L_{p_{-} h}, L_{p_{-} m}$ and $L_{p_{-} l}$, which can impact the current commutation during the switching transient.

2) Stage 2: Complete parasitic model.

In the analytical model, joint node is represented by starconfigured inductance, as shown in Fig. 3(b). $L_{d_{-} h}, L_{s_{-} h}$ and $L_{d \_l}, L_{s_{-} l}$ are generally recognized as transistor drain/source inductance [24]. Common source inductance is widely studied, and defined as inductance of the common conductor shared between the transistor gate loop and power loop. Lead inductance of the transistor package contributes to the majority of common source inductance, which is widely studied in the through hole packaged Silicon and Silicon Carbide (SiC) transistors [23], [25]. For GaN transistors, surface-mounted chip scale package and Kelvin connection are generally used by manufacturers. Impact of the common source inductance can be neglected in the discrete $\mathrm{GaN}$ transistor applications. Furthermore, drain inductance and source inductance cannot be distinguished and quantified within the scope of PCB tracks, which is not suitable in GaN transistor modeling.

3) Stage 3: Simplified lump inductance model.

In a practical approach, FEA tools are widely used to quantify the power loop inductance [26], [27]. $L_{p_{-} 1}, L_{p_{-} 2}$ and $L_{p \_m}$ are used to compose the power loop inductance and the simplified lump inductance model is obtained as Fig. 3(c). This model can be viewed as the simplification of Stage 1 analytical model, which only considers the critical inductance within power loop and guarantees the simulation accuracy during the switching transient. The FEA method is widely considered accurate, but yet time-consuming. For the high frequency FEA simulation, skin effect requires fine mesh operation and leads to considerate computational load. Also, it should be mentioned that the lump inductance solved in FEA tools is partial inductance, where a $\mathrm{n} \times \mathrm{n}$ inductance matrix is generally obtained from the power loop composed by $n$ pieces of conductors. Both self and mutual partial partial inductance are affected by the geometry placement of PCB tracks, which cannot be used as an intuitive tool for layout optimization.

4) Stage 4: Simplified loop inductance model.

Instead of solving the lump inductance model in FEA tools, simplified loop inductance model is introduced as Fig. 3(d). The whole power loop is equivalent as one parasitic inductor $L_{\text {loop }}$ during the switching transient. Location of $L_{\text {loop }}$ within the power loop has no impact on the transistor voltage ringing, which is sufficient for layout comparison and guarantees the same simulation accuracy as the stage 3 lump inductance model. By using this model, the FEA simulation is simplified as solving the self inductance of one equivalent conductor. Also, this model provides the basis for numerical estimation, which will be illustrated in the following part.

\section{B. Numerical Equation for Power Loop Inductance Estimation}

Equivalent conductor is proposed as one close loop conductor, which has the same material and dimensions with

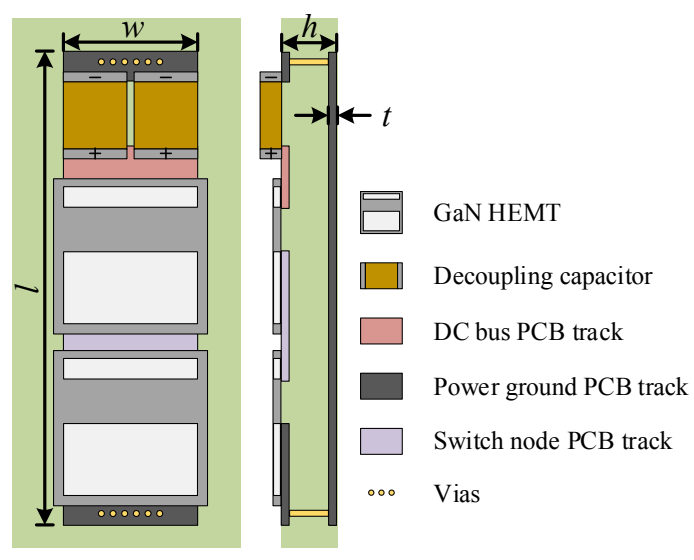

Fig. 4. Vertical PCB layout in [16].

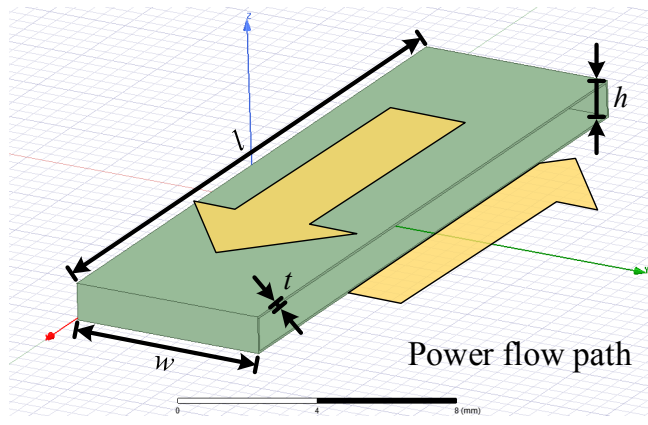

Fig. 5. Power loop equivalent conductor.

the power loop PCB tracks. Inductance of the equivalent conductor can be used as a fast approximation of the practical power loop inductance. For instance, the typical vertical layout shown in Fig. 4 can be equivalent to the equivalent conductor shown in Fig. 5. Parameters $h, w, l$ and $t$ are decided by the geometry dimensions of the GaN transistor package, the decoupling capacitor and the PCB layer stackup, which can be directly obtained from the data sheet and PCB layout. Instead of solving the inductance matrix based on Stage 3 lump inductance model, solving the loop inductance in Stage 4 model can largely reduces the simulation time and provides the basis for parameters sweep.

The concept of equivalent conductor can be further used for numerical quantification of the power loop inductance. The challenge of numerical derivation based on Maxwell equation lies in the description of current distribution. Oscillation frequency within the power loop can be addressed by

$$
f_{\text {ringing }}=\frac{1}{2 \pi \sqrt{L_{\text {loop }} C_{\text {oss }}}},
$$

where $L_{\text {loop }}$ is the power loop inductance and $C_{\text {oss }}$ is the transistor output capacitance. The low parasitic parameters of the $\mathrm{GaN}$ transistor power loop leads to the ringing frequency ranging around several hundred $\mathrm{MHz}$. In the high frequency oscillation, conductor skin depth $\delta$ can be obtained as

$$
\delta=\sqrt{\frac{\rho}{\pi f_{\text {ringing }} \mu_{r} \mu_{0}}},
$$




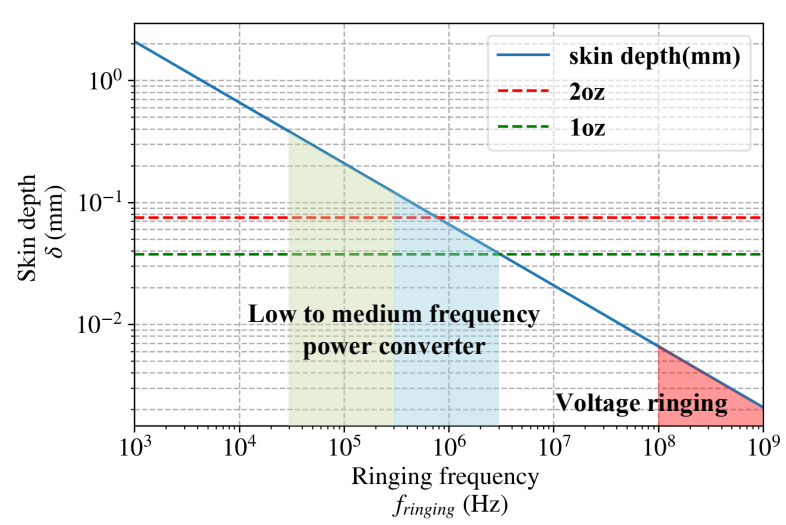

Fig. 6. Parasitic inductance of the switch node in delta connection.

TABLE I

Default Value of The Parameters SWeeP

\begin{tabular}{c|c|c|c}
\hline \hline$h$ & $w$ & $l$ & $t$ \\
\hline $1 \mathrm{~mm}$ & $6 \mathrm{~mm}$ & $20 \mathrm{~mm}$ & $0.07 \mathrm{~mm}$ \\
\hline \hline
\end{tabular}

where $\rho$ is the resistivity and $\mu_{r}$ is the relative permeability of the conductor. The skin depth of the copper conductor is plotted against the frequency spectrum as shown in Fig. 6. Within frequency range of the $\mathrm{GaN}$ transistor power loop oscillation, the skin depth is already much lower than the 1 oz copper thickness. Accurate numerical description of the current distribution is challenged by the rectangular shape of the PCB track cross-section.

Facing the dilemma addressed above, a trade-off solution between the FEA simulation and the numerical derivation is proposed based on the Stage 4 loop inductance model. The equivalent conductor model is first imported into ANSYS Maxwell for FEA simulation. Based on the default value given in TABLE I, FEA simulation results of the parameters sweep is shown as Fig. 7. FEA simulation frequency is set to be $500 \mathrm{MHz}$ and loop inductance is proved irrelevant to the oscillation frequency within the hundreds $\mathrm{MHz}$ range as shown in Fig. 7(c). Fine mesh operation of the equivalent conductor is applied in the FEA simulation setup according to the calculated skin depth at the frequency of the GaN transistor voltage ringing. Power loop inductance is proportional to the conductor length and irrelevant to the copper thickness for the skin effect as shown in Fig. 7(a) and Fig. 7(b).

Parameter sweep of $h$ and $w$ is then carried out to obtain the power loop inductance. $h$ and $w$ are the height and width of the equivalent conductor. To provide a general equation for the GaN transistor power loop inductance estimation, the parameters sweep range is summarized in TABLE II. Sweep

TABLE II GEOMETRY PARAMETER SWEEP

\begin{tabular}{c|c}
\hline \hline$h$ & $\begin{array}{c}0.1-0.3 \mathrm{~mm} \text { (0.05 mm spacing) } \\
0.5-4 \mathrm{~mm} \text { (0.5 mm spacing) }\end{array}$ \\
\hline$w$ & $1-15 \mathrm{~mm}$ (1 mm spacing) \\
\hline \hline
\end{tabular}

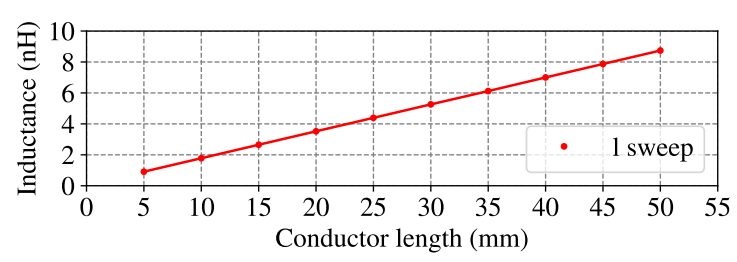

(a) Conductor length $l$ sweep.

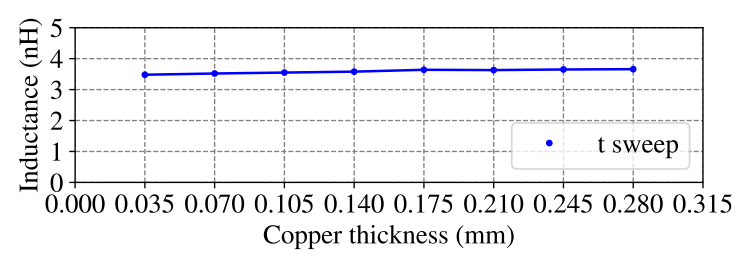

(b) Copper thickness $t$ sweep.

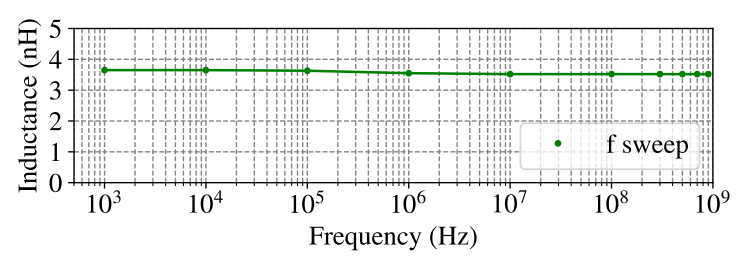

(c) Frequency $f$ sweep.

Fig. 7. FEA results of the conductor parameters sweep.

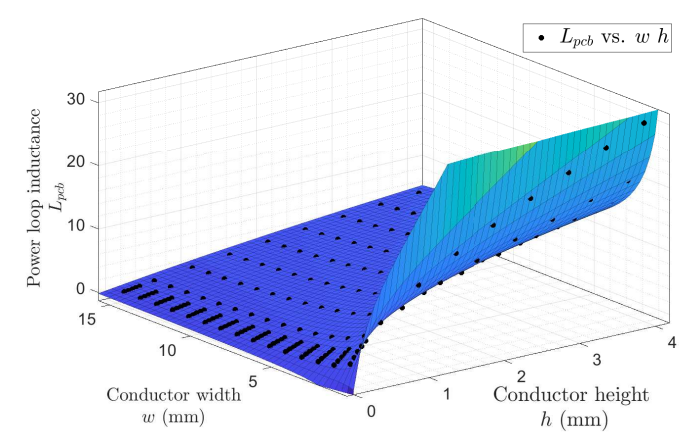

Fig. 8. Curve fitting of the FEA results given in MATLAB.

range of $w$ is decided according to the package dimension of $\mathrm{GaN}$ transistors, covering all the commercial available eGaN transistor models from EPC and GaN Systems. Sweep range of $h$ is decided by the general range of distance between PCB layers and board thickness, which is collected from the PCB manufacturer. By applying the default geometry shown in TABLE I and the parameters sweep shown in TABLE II, all together 195 sets of loop inductance are solved through ANSYS Maxwell FEA simulation. Using (1) as the starting point, curve fitting of the FEA results is carried out by MATLAB as shown in Fig. 8.

$$
L_{\text {loop }} \cong \mu_{0} \frac{h}{w} l\left(\frac{0.27}{1-0.74 \cdot e^{-0.45(h / w)}}\right)
$$

Based on the logistic correction model, customized equation for the power loop inductance estimation can be obtained as (4). Estimation accuracy is corroborated by the high $R^{2}$ value 


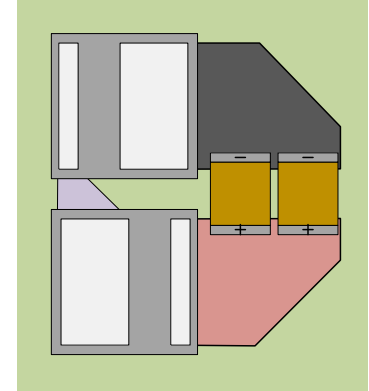

(a) Conventional layout

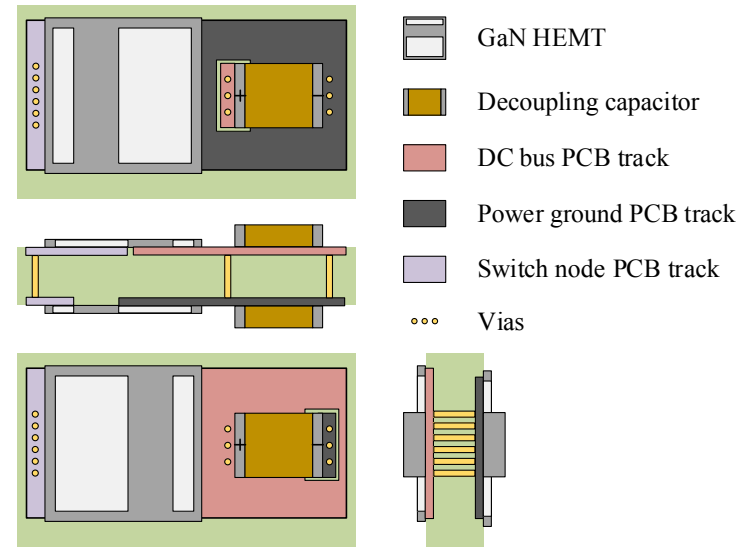

(c) Minimal layout.

Fig. 9. Power loop layout comparison.

of 0.9992 , which is close to the ideal estimation condition $R^{2}=1$.

\section{POWER LOOP LAYOUT COMPARISON}

\section{A. Layout Comparison}

Three different layout methods are compared in this section, including one conventional layout, one low inductance layout proposed in the prior-art research and one minimal layout method proposed in this paper. The conventional layout is shown in Fig. 9(a). All the components (decoupling capacitors and transistors) are placed on the top side of PCB and the power loop is conducted within the same PCB layer. Vertical layout shown in Fig. 9(b) can effectively reduce the power loop inductance by designing the conduction loop within two PCB layers. The reduced power loop inductance is explained in [16] as the magnetic canceling between the two conduction layers. In a further step of power loop minimization, the minimal layout is proposed as shown in Fig. 9(c). Two transistors are placed back to back on the two sides of PCB. The decoupling capacitors are also placed symmetrically on double sides of the PCB to minimize the power loop.

Using the loop inductance model and equation (4), the power loop inductance can be easily estimated from the geometry information of the power loop layout. As shown in TABLE III, three e-GaN transistors of different voltage ratings and one parallel $\mathrm{GaN}$ transistor configuration are
TABLE III

ESTIMATED LOOP INDUCTANCE

\begin{tabular}{c|c|c|c}
\hline \hline & $\begin{array}{c}\text { Voltage rating } \\
V_{d s} / \mathrm{V}\end{array}$ & $\begin{array}{c}\text { Vertical layout } \\
L_{\text {loop_}} V / \mathrm{nH}\end{array}$ & $\begin{array}{c}\text { Minimal layout } \\
L_{\text {loop_}} M / \mathrm{nH}\end{array}$ \\
\hline EPC2024 & 40 & 1.2 & 0.8 \\
\hline EPC2029 & 80 & 1.7 & 1.1 \\
\hline GS66504B & 650 & 2.9 & 2.2 \\
\hline GS66504B*2 & 650 & 1.5 & 1.0 \\
\hline \hline
\end{tabular}

selected for illustration. $L_{l o o p_{-} V}$ and $L_{l o o p_{-} M}$ are the power loop inductance of the vertical layout and the minimal layout respectively, which are estimated based on the dimensions of the decoupling capacitors and the GaN transistors. Decoupling capacitors adopt 1206 and 0805 package respectively for the $\mathrm{GaN}$ transistor rated at $650 \mathrm{~V}$ and $100 \mathrm{~V}$ (or lower). From the estimation results, both layout methods can maintain the power loop inductance less than $4 \mathrm{nH}$. The proposed minimal layout can further reduce the power loop inductance by 30 - $40 \%$ compared with the vertical layout. In high power applications, paralleling transistors is needed to balance the thermal dissipation in each distributed semiconductor. One critical consideration is symmetrical PCB layout, which can guarantee identical parasitic component between each paralled branch and thus enhance current balancing capability. As a result, vertical layout and minimal layout are more favorable in this situation. As shown in TABLE III, extra paralleled transistor widen the conduction power loop and parasitic power loop inductance can be further reduced.

Parasitic capacitance in PCB layout is resulted from the vertical overlap between different $\mathrm{PCB}$ tracks, which may add up to the transistor output capacitance and lead to extra switching loss. For conventional layout, all three PCB tracks shown in Fig. 9(a) are placed within one PCB plane and parasitic capacitance can be neglected. In the vertical layout shown in Fig. 9(b), vertical overlap between switch node PCB track and power ground $\mathrm{PCB}$ track add parasitic capacitance to the low side transistor. DC bus PCB track can also be coupled to the switch node via the power ground plane, which will add parasitic capacitance to the high side transistor. Based on vertical layout of GS66504B in $1 \mathrm{~mm}$ thick FR4 PCB board, we can estimate the parasitic capacitance according to $(5)$ ( $A$ is PCB track area, $d$ is vertical distance and relative permittivity of FR4 PCB $\epsilon=4.4$ ).

$$
C=\varepsilon \cdot \varepsilon_{0} \cdot \frac{A}{d}
$$

Parasitic capacitance of $1.35 \mathrm{pF}$ and $0.36 \mathrm{pF}$ is added to the low side and high side transistor respectively in the vertical layout, which is tolerable in current configuration (GS66504B $\left.C_{\text {oss }}=31 \mathrm{pF}\right)$. However, parasitic capacitance in vertical layout can be exaggerated in a thinner PCB board layout or adjacent layer ground plane placement. Minimal layout, on the other hand, is not affected by parasitic capacitance. As shown in Fig. 9(c), vertical overlap only exist between the DC bus $\mathrm{PCB}$ track and power ground PCB track, where parasitic 

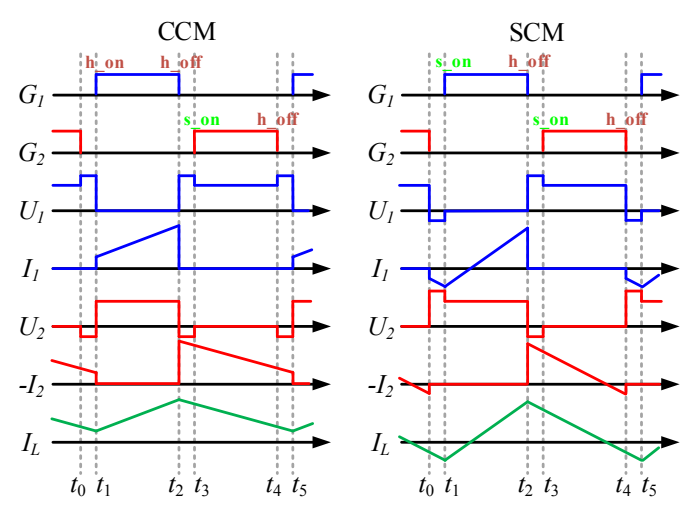

Fig. 10. Ideal waveform of the synchronous buck converter.

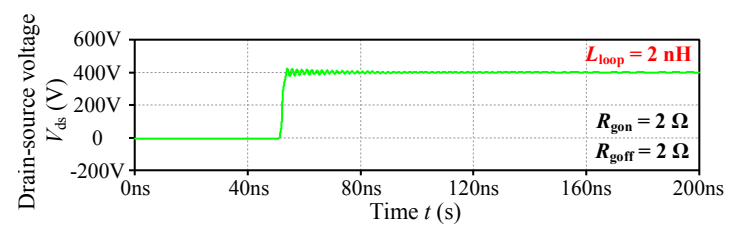

(a)

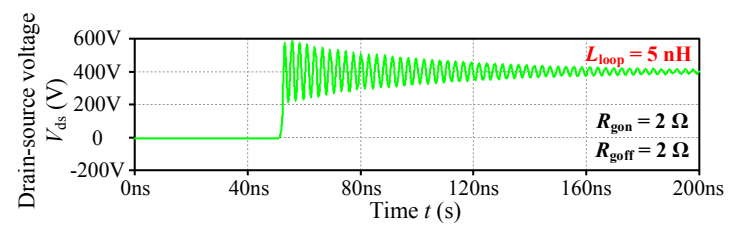

(b)

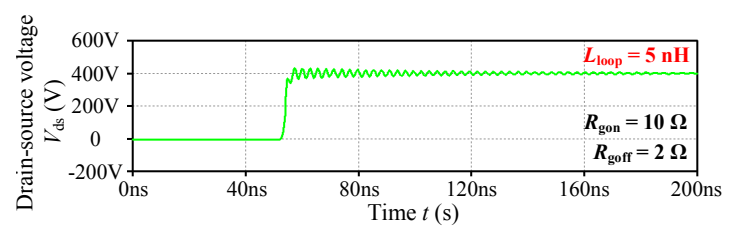

(c)

Fig. 11. Drain-source voltage ringing in the low side transistor (GS66504B, $650 \mathrm{~V}, 15 \mathrm{~A})$ during CCM operation.

capacitance is added parallel to the decoupling capacitor and has no impact on the transistor switching.

\section{B. Impact of Power Loop Inductance in Converter Operation}

Influence of the power loop inductance is discussed over the synchronous buck converter topology as shown in Fig. 3. The synchronous buck converter has two operation modes: continuous conduction mode (CCM) and synchronous conduction mode (SCM), the ideal waveform of which is shown in Fig. 10. $G_{1}$ and $G_{2}$ are the gate signal of the high-side and low-side transistor. Hard switching or soft switching is noted besides the gate pulses. $U_{1}, U_{2}$ and $I_{1}, I_{2}$ are the drain-source voltage and source current of the high-side and low-side transistor respectively. $I_{L}$ is the inductor current.

Transistor voltage ringing is concerned during the hard switching transient, where drain-source voltage ringing can be observed in the low side transistor at CCM operation. During this transient, energy stored in high side transistor output capacitor is discharged within the power loop. Power loop
TABLE IV

SWITCHING CONDITION OF SYNCHRONOUS BUCK CONVERTER

\begin{tabular}{c|c|c|c}
\hline \hline Input voltage / V & 400 & Output voltage / V & 200 \\
\hline Output power / W & 300 & Output current / A & 1.5 \\
\hline Switching frequency / kHz & 100 & Dead time /ns & 100 \\
\hline \hline
\end{tabular}

TABLE V

TRANSISTOR LOSS COMPARISON

\begin{tabular}{c|c|c|c|c|c}
\hline \hline$L_{\text {loop }} / \mathrm{nH}$ & 1 & 2 & 3 & 4 & 5 \\
\hline $\begin{array}{c}\text { Transistor loss } \\
\text { during CCM / W }\end{array}$ & 1.52 & 1.52 & 1.51 & 1.48 & 1.45 \\
\hline $\begin{array}{c}\text { Transistor loss } \\
\text { during SCM / W }\end{array}$ & 1.08 & 1.1 & 1.14 & 1.34 & 1.43 \\
\hline
\end{tabular}

inductance is resonant with the output capacitor of the low side transistor and lead to drain-source voltage ringing in the low side transistor. LTSpice simulation result is given to illustrate the impact of power loop inductance in the drain-source voltage ringing. GS66504B (e-GaN transistor, $650 \mathrm{~V}, 15 \mathrm{~A}$ ) is used in the simulation. Power loop inductance is modeled as the stage 4 model given in Fig. 3(d). Comparison of the drain-source voltage ringing is given in LTSpice simulation shown in Fig. 11, where $R_{\text {gon }}$ and $R_{\text {goff }}$ are the gate-on and gate-off resistor respectively. When the power loop inductance is increased, the power loop oscillation is increased and the percentage overshoot of drain-source voltage is higher. In the case shown in Fig. 11(b), the transistor is rated at $650 \mathrm{~V}$ and can be potentially damaged by the over-voltage switching. This drain-source voltage overshoot can be suppressed by large gate resistor selection at the cost of larger switching loss.

Power loop inductance also impact on the transistor power loss. To provide an intuitive comparison, high side transistor power loss is calculated in LTSpice simulation based on specifications listed in TABLE IV. During CCM operation, high side transistor is hard switched and switching loss is reduced in a higher power loop inductance, as shown in TABLE V. During the hard switching transient, transistor source current commutation is delayed by power loop inductance and voltage-current overlap is reduced. However, its impact on switching loss reduction is limited. Minimization of power loop inductance to reduce drain-source voltage ringing is still the major concern in hard switching applications. During the SCM operation mode, both high side and low side transistor is soft switched. Large power loop inductance brings extra transistor power loss, which is evident during the soft switching condition. This phenomenon is explained as the soft-switching losses in [28]. Considering the limited power dissipation capability of the GaN transistor, minimization of power loop inductance is also important in the soft switching applications.

\section{EXPERIMENTAL VALIDATION}

\section{A. Modular Buck Converter}

A GaN based synchronous buck converter is designed to verify the numerical loop inductance calculation method and 


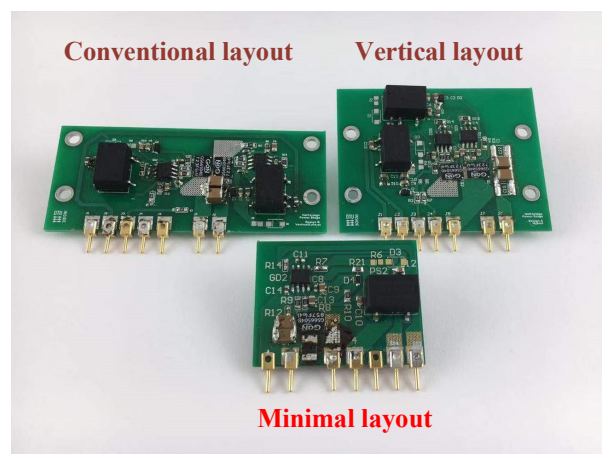

Fig. 12. Daughter boards designed from three power loop layout methods.

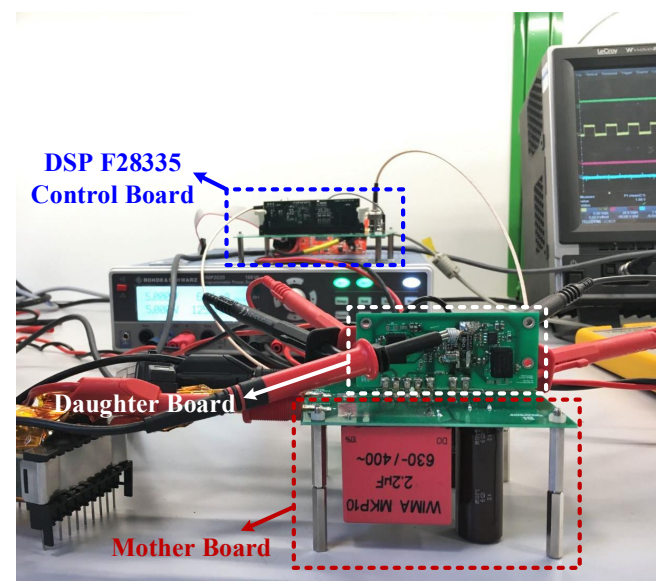

Fig. 13. Experimental setup.

the proposed minimal power loop layout. GS66504B e-GaN transistor is used for demonstration. Modular design is adopted to guarantee the identical test conditions. The half bridge transistors and decoupling capacitors, along with the gate driver and digital power supply, are placed on the daughter board. The rest of the buck converter, including the DC bus capacitor and the output filter, are placed on the motherboard. Conventional layout, vertical layout and minimal layout are adopted respectively to design the three daughter boards, as shown in Fig. 12. Daughter board by the proposed minimal layout is the smallest design compared with two other boards by the conventional method. Modular buck converter setup is shown in Fig. 13. Digital controller DSP F28335 is used to apply the gate signals via BNC coaxial cable. Lecroy passive probe $(400 \mathrm{MHz}$ band width, parasitic capacitance $<6 \mathrm{pF}$ ) is used to accurately measure the voltage signal. Pigtail ground wire is used to minimize the parasitic inductance introduced from the probe ground connection.

\section{B. Power Loop Inductance Comparison}

The power loop inductance of each layout is estimated from the low side transistor drain-source voltage ringing during the DCM operation mode. For the measurement accuracy, the DC bus voltage is set to be $50 \mathrm{~V}$. As shown in Fig. 14, the transistor output capacitance is relatively large at $50 \mathrm{~V}$, which leads to a measurable drain-source voltage ringing frequency ranging from 100 to $200 \mathrm{MHz}$ as shown in Fig. 14(a). An external
TABLE VI

POWER LOOP INDUCTANCE COMPARISON

\begin{tabular}{c|c|c|c|c}
\hline \hline \multicolumn{2}{c|}{} & Conventional & Vertical & Minimal \\
\hline \multirow{2}{*}{ Measurement } & $f_{0} / \mathrm{MHz}$ & 194 & 220 & 263 \\
\cline { 2 - 5 } & $f_{1} / \mathrm{MHz}$ & 145 & 165 & 196 \\
\hline \multirow{2}{*}{$\begin{array}{c}\text { Calculation } \\
\text { by (6) }\end{array}$} & $C_{\text {oss }} / \mathrm{pF}$ & 189.9 & 192.9 & 187.4 \\
\cline { 2 - 5 } & $L_{\text {loop }} / \mathrm{nH}$ & 3.6 & 2.7 & 2.0 \\
\hline $\begin{array}{c}\text { Estimation } \\
\text { by (4) }\end{array}$ & $L_{\text {loop }} / \mathrm{nH}$ & $\mathrm{NA}$ & 2.9 & 2.2 \\
\hline
\end{tabular}

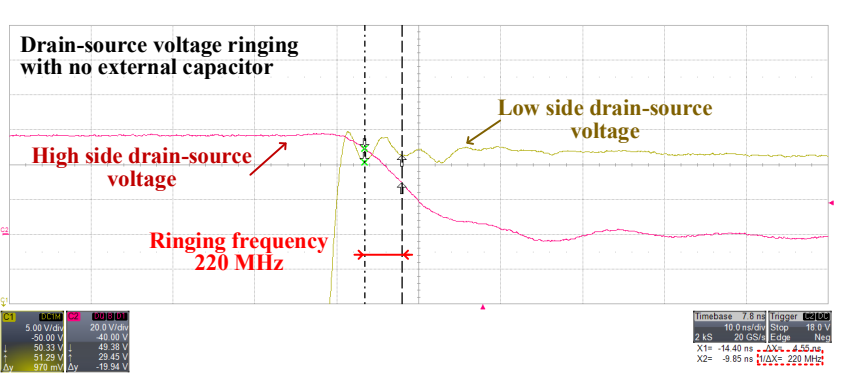

(a)

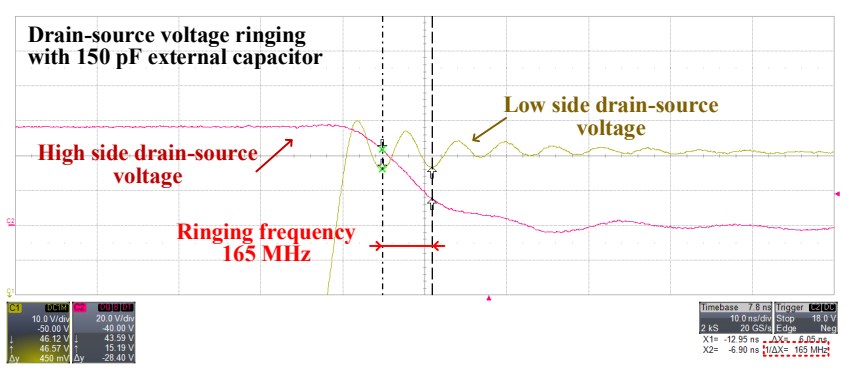

(b)

Fig. 14. Measured drain-source voltage ringing of vertical layout at $50 \mathrm{~V} \mathrm{DC}$ bus.

capacitor $\left(C_{e x}=150 \mathrm{pF}\right)$ is then paralleled to the low-side transistor and the drain-source voltage ringing frequency is further lowered as shown in 14(b). Power loop inductance $\left(L_{\text {loop }}\right)$ and transistor output capacitance $\left(C_{o s s}\right)$ can thus be solved respectively according to (6).

$$
\left\{\begin{array}{c}
f_{0}=1 / 2 \pi \sqrt{L_{\text {loop }} C_{o s s}} \\
f_{1}=1 / 2 \pi \sqrt{L_{\text {loop }}\left(C_{\text {oss }}+C_{e x}\right)}
\end{array}\right.
$$

The ringing test is repeated on the three daughter boards respectively at the same switching condition and the test results are summarized in TABLE VI. $f_{0}$ and $f_{1}$ are the measured ringing frequency of the drain-source voltage without and with the external capacitor respectively. The estimated transistor output capacitance shows a consistency between three different boards at $50 \mathrm{~V}$, which is also consistent with the output capacitance characterization curve given in the manufacturer data sheet. The proposed minimal layout shows the lowest power loop inductance. Compared with the conventional layout, power loop inductance is reduced by $25 \%$ when applying the vertical layout and $44 \%$ when applying the proposed minimal layout. Power loop inductance of the vertical layout and the minimal layout can be estimated by applying the numerical equation given in (4). Compared with the calculated 


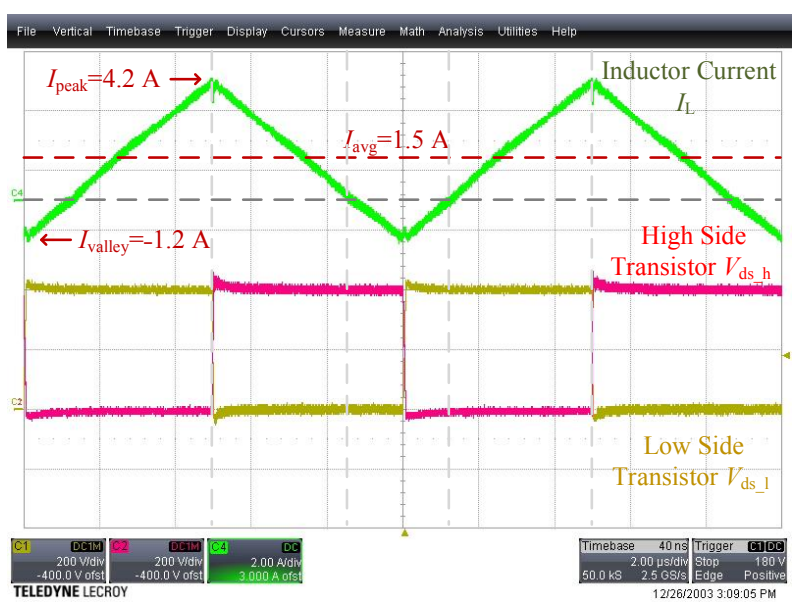

Fig. 15. Experimental waveform of the modular buck converter.

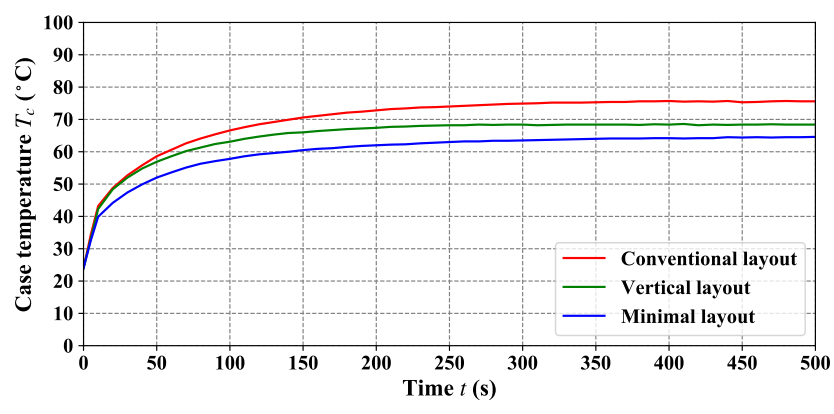

Fig. 16. GaN transistor temperature ramping during thermal test.

value from the experimental results, the proposed numerical equation shows a percentage deviation less than $7 \%$, which is low to $0.2 \mathrm{nH}$ considering the small power loop inductance value.

\section{Thermal Comparison}

Impact of power loop inductance on the transistor power loss is examined by thermal comparison. By applying identical copper expansion and thermal via suggested by the manufacturer application note, thermal dissipation can be examined by infrared image to evaluate the power loss of each layout configuration. At the switching condition specified in TABLE IV, experimental waveform of the modular buck converter is given in Fig. 15. Buck converter operates at CCM and a resistive load is fixed at $300 \mathrm{~W}$. Thermal dissipation in each daughter board is examined without head sink and forced air convection at room temperature of $24^{\circ} \mathrm{C}$.

Transistor case temperature is measured every 10 seconds during the thermal test as shown in Fig. 16. Thermal equilibrium is reached after 5 minutes of continuous operation and stabilized heat distribution of each layout configuration is obtained as shown in Fig. 17. While exactly the same components are used between three daughter boards, minimal layout shows the lowest transistor case temperature, which is $10.5{ }^{\circ} \mathrm{C}$ lower than the conventional layout. Besides the thermal comparison at fixed load power, output power of each daughter board is then pushed to the thermal limit,

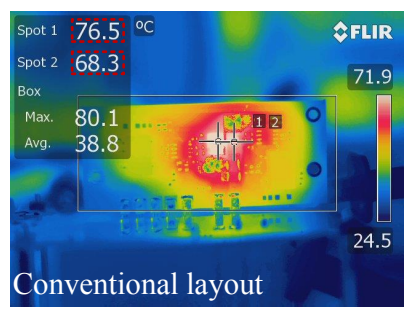

(a)

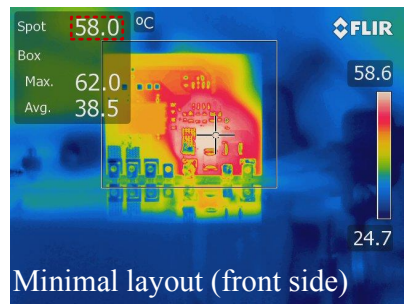

(c)

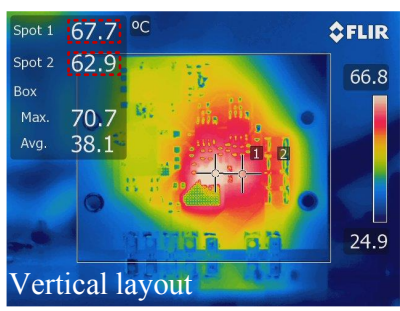

(b)

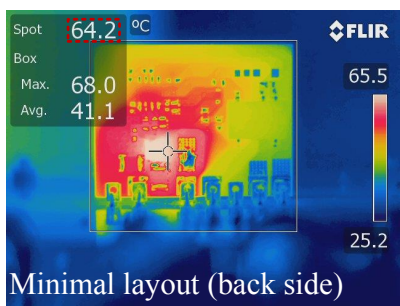

(d)
Fig. 17. Comparison of the temperature distribution between daughter boards.

which is restricted by the transistor junction temperature. From the manufacture data sheet, the rated junction temperature of GS66504B is specified as $-55{ }^{\circ} \mathrm{C}$ to $+150{ }^{\circ} \mathrm{C}$ and the junctiontop thermal resistance is specified to be $17 \mathrm{~K} / \mathrm{W}$. Accordingly, the criteria for maximum power rate is defined when the transistor top-side case temperature reaches $100{ }^{\circ} \mathrm{C}$, which is a close approach to the junction thermal limit referred from the estimated transistor power loss.

As shown in TABLE VII, minimal layout shows the maximum power capability. A total load power of $440 \mathrm{~W}$ can be handled within one single half bridge, which is well suited to the majority of lower power and soft-switching GaN transistor applications. Without heat sink attachment, minimal layout shows benefit of low power loop inductance, low profile and high power capacity compared with conventional and vertical layout. In the high power application, where heat sink and forced air convection are essential, selection of the transistor model with suitable cooling solution is important. $\mathrm{GaN}$ transistors are generally classified into top cooling device and bottom cooling device, depending on the physical location of cooling pad in the transistor package. Thermal vias are generally used to provide a heat conduction path from transistor cooling pad to heat sink attached to the bottom side of PCB. For vertical and minimal layout, thermal vias may interfere with the power loop conduction path and top cooling device is more favorable in these two cases. Thermal interface material (TIM) is generally applied to provide electric insulation between the transistor cooling pad and the heat sink. By selecting soft texture TIM with a proper thickness, air gap between these two mating surfaces can also be eliminated to provide a low thermal resistance path. Mounting of heat sink to the top cooling device may interfere with the power loop layout and potentially increase the power loop inductance, which is a trade-off between the thermal design and electric performance. This is alleviated by the TIM enclosure thermal design proposed in [32], [33]. 
TABLE VII

COMPARISON OF THERMAL DISSIPATION

\begin{tabular}{c|c|c|c}
\hline \hline & Conventional layout & Vertical layout & Minimal layout \\
\hline Maximum Tc @ 300W output & $76.5{ }^{\circ} \mathrm{C}$ & $67.7{ }^{\circ} \mathrm{C}$ & $64.2{ }^{\circ} \mathrm{C}$ \\
\hline $\begin{array}{c}\text { Maximum power capacity } \\
\text { without heatsink }\end{array}$ & $388 \mathrm{~W}$ & $430 \mathrm{~W}$ & $443 \mathrm{~W}$ \\
\hline $\begin{array}{c}\text { Heat sink installation } \\
\text { for bottom cooling device }\end{array}$ & $\begin{array}{c}\text { Thermal vias } \\
{[13],[29],[30]}\end{array}$ & Not applied \\
\hline $\begin{array}{c}\text { Heat sink installation } \\
\text { for top cooling device }\end{array}$ & $\begin{array}{c}\text { Thermal interface material attachment/enclosure method } \\
{[15],[27],[31]-[34]}\end{array}$ \\
\hline
\end{tabular}

\section{Conclusions}

Power loop inductance in the $\mathrm{GaN}$ based converters is thoroughly investigated in this paper. Methodology of the power loop inductance modeling is illustrated step by step in 4 stages. Based on the loop inductance model, a numerical equation is acquired as a fast estimation approach for the power loop inductance quantification. The proposed equation can be easily applied to various $\mathrm{GaN}$ transistor applications and proves to be accurate with a low percentage deviation $(<7 \%)$ compared with the experimental results. In comparison with two other PCB layout methods from the priorart research, a minimal PCB layout method is proposed to further reduce the power loop inductance and its effectiveness is validated on a modular buck converter. By adopting the minimal layout, the power loop inductance can be reduced to $2 \mathrm{nH}$ for GS66504B GaN transistor application, which is 44 $\%$ smaller than the conventional layout. Meanwhile, compared with vertical layout, minimal layout avoids adding extra switch node parasitic capacitance. High frequency ringing in the drain-source voltage is effectively suppressed by the proposed method. For the specified test conditions of the modular buck converter, the minimal layout helps to lower the transistor operation temperature by $10{ }^{\circ} \mathrm{C}$ and increase the maximum power capacity of the modular buck converter by $14 \%$ compared with the conventional layout.

\section{REFERENCES}

[1] A. Nawawi, C. F. Tong, S. Yin, A. Sakanova, Y. Liu, Y. Liu, M. Kai, K. Y. See, K. J. Tseng, R. Simanjorang, C. J. Gajanayake, and A. K. Gupta, "Design and Demonstration of High Power Density Inverter for Aircraft Applications," IEEE Transactions on Industry Applications, vol. 53, no. 2, pp. 1168-1176, 2017.

[2] M. Danilovic, Z. Chen, R. Wang, F. Luo, D. Boroyevich, and P. Mattavelli, "Evaluation of the switching characteristics of a gallium-nitride transistor," IEEE Energy Conversion Congress and Exposition: Energy Conversion Innovation for a Clean Energy Future, ECCE 2011, Proceedings, pp. 2681-2688, 2011.

[3] H. Meşe and I. Çadırcı, "Natural-air-cooled 5 kVA single-phase GaN inverter with paralleled multilayer PCB magnetics," The Journal of Engineering, vol. 2018, no. 2, pp. 94-103, feb 2018.

[4] K. A. Kim, "Opening the Box: Survey of High Power Density Inverter Techniques From the Little Box Challenge," CPSS Transactions on Power Electronics and Applications, vol. 2, no. 2, pp. 131-139, 2017.

[5] X. Huang, Q. Li, Z. Liu, and F. C. Lee, "Analytical loss model of high voltage GaN HEMT in cascode configuration," IEEE Transactions on Power Electronics, vol. 29, no. 5, pp. 2208-2219, 2014.

[6] J. Wang and H. Shu-Hung Chung, "Impact of parasitic elements on the spurious triggering pulse in synchronous buck converter," IEEE Transactions on Power Electronics, vol. 29, no. 12, pp. 6672-6685, 2014.
[7] A. Kulkarni, A. Gupta, and S. K. Mazumder, "Resolving Practical Design Issues in a Single-Phase Grid-Connected GaN-FET Based Differential-Mode Inverter,' IEEE Transactions on Power Electronics, vol. 33, no. 5, pp. 3734-3751, 2017.

[8] W. Zhang, X. Huang, F. C. Lee, and Q. Li, "Gate drive design considerations for high voltage cascode GaN HEMT," Conference Proceedings - IEEE Applied Power Electronics Conference and Exposition - APEC, pp. 1484-1489, 2014.

[9] P. M. Roschatt, S. Pickering, and R. A. McMahon, "Bootstrap Voltage and Dead Time Behavior in GaN DC-DC Buck Converter With a Negative Gate Voltage," IEEE Transactions on Power Electronics, vol. 31, no. 10 , pp. 7161-7170, oct 2016 .

[10] R. Hou, J. Xu, and D. Chen, “A multivariable turn-on/turn-off switching loss scaling approach for high-voltage GaN HEMTs in a hard-switching half-bridge configuration," 2017 IEEE 5th Workshop on Wide Bandgap Power Devices and Applications, WiPDA 2017, vol. 2017-Decem, pp. 171-176, 2017.

[11] A. Gupta and S. K. Mazumder, "GaN-FET based grid-connected solar microinverter: Some design insights," 2017 IEEE 5th Workshop on Wide Bandgap Power Devices and Applications (WiPDA), pp. 233-237, 2017.

[12] E. A. Jones, F. Wang, D. Costinett, Z. Zhang, and B. Guo, "Cross conduction analysis for enhancement-mode 650-V GaN HFETs in a phase-leg topology," WiPDA 2015 - 3rd IEEE Workshop on Wide Bandgap Power Devices and Applications, pp. 98-103, 2015.

[13] E. A. Jones, P. Williford, Z. Yang, J. Chen, F. Wang, S. Bala, J. Xu, and J. Puukko, "Maximizing the voltage and current capability of GaN FETs in a hard-switching converter," Proceedings of the International Conference on Power Electronics and Drive Systems, vol. 2017-Decem, no. December, pp. 740-747, 2018.

[14] A. B. Jorgensen, S. Beczkowski, C. Uhrenfeldt, N. H. Petersen, S. Jorgensen, and S. Munk-Nielsen, "A Fast-Switching Integrated Full-Bridge Power Module Based on GaN eHEMT Devices," IEEE Transactions on Power Electronics, vol. 1, no. c, 2018.

[15] H. Li, X. Li, Z. Zhang, C. Yao, and J. Wang, "Design consideration of high power GaN inverter," WiPDA 2016 - 4th IEEE Workshop on Wide Bandgap Power Devices and Applications, pp. 23-29, 2016.

[16] D. Reusch and J. Strydom, "Understanding the effect of PCB layout on circuit performance in a high frequency gallium nitride based point of load converter," IEEE Transactions on Power Electronics, vol. PP, no. 99, p. 1, 2013.

[17] E. Gurpinar, F. Iannuzzo, Y. Yang, A. Castellazzi, and F. Blaabjerg, "Design of Low-Inductance Switching Power Cell for GaN HEMT Based Inverter," IEEE Transactions on Industry Applications, vol. 54, no. 2, pp. 1592-1601, 2018.

[18] J. L. Lu, R. Hou, and D. Chen, "Opportunities and design considerations of GaN HEMTs in ZVS applications," Conference Proceedings - IEEE Applied Power Electronics Conference and Exposition - APEC, vol. 2018-March, pp. 880-885, 2018.

[19] E. Gurpinar and A. Castellazzi, "Tradeoff Study of Heat Sink and Output Filter Volume in a GaN HEMT Based Single-Phase Inverter," IEEE Transactions on Power Electronics, vol. 33, no. 6, pp. 5226-5239, jun 2018.

[20] K. Wang, L. Wang, X. Yang, X. Zeng, W. Chen, and H. Li, “A Multiloop Method for Minimization of Parasitic Inductance in GaN-Based HighFrequency DC-DC Converter," IEEE Transactions on Power Electronics, vol. 32, no. 6, pp. 4728-4740, 2017.

[21] A. Letellier, M. Dubois, J. P. F. Trovao, and H. Maher, "Calculation of PCB Power Loop Stray Inductance in GaN or High di/dt Applications," IEEE Transactions on Power Electronics, vol. 8993, no. c, p. 1, 2018. 
[22] J. Clayton R. Paul; Goedbloed, "Partial Inductance," Physics in Technology, vol. 18, no. 2, pp. 61-67, 1987.

[23] A. Anthon, J. C. Hernandez, Z. Zhang, and M. A. Andersen, "Switching investigations on a SiC MOSFET in a TO-247 package," IECON Proceedings (Industrial Electronics Conference), no. July 2015, pp. 1854-1860, 2014.

[24] K. Wang, X. Yang, H. Li, H. Ma, X. Zeng, and W. Chen, "An Analytical Switching Process Model of Low-Voltage eGaN HEMTs for Loss Calculation," IEEE Transactions on Power Electronics, vol. 31, no. 1, pp. 635-647, 2016.

[25] Yuancheng Ren, Ming Xu, Jinghai Zhou, and F. Lee, "Analytical loss model of power MOSFET," IEEE Transactions on Power Electronics, vol. 21 , no. 2, pp. 310-319, mar 2006

[26] B. Sun, R. Burgos, X. Zhang, and D. Boroyevich, "Active dv/dt control of $600 \mathrm{~V}$ GaN transistors," in 2016 IEEE Energy Conversion Congress and Exposition (ECCE). IEEE, sep 2016, pp. 1-8.

[27] H. Li, X. Zhang, Z. Zhang, C. Yao, F. Qi, B. Hu, J. Wang, and L. Liu, "Design of a $10 \mathrm{~kW}$ GaN-based high power density threephase inverter," ECCE 2016 - IEEE Energy Conversion Congress and Exposition, Proceedings, 2016.

[28] G. Zulauf, S. Park, W. Liang, K. N. Surakitbovorn, and J. Rivas-Davila, "COSS Losses in 600 v GaN Power Semiconductors in Soft-Switched, High- and Very-High-Frequency Power Converters," IEEE Transactions on Power Electronics, vol. 33, no. 12, pp. 10748-10763, 2018.

[29] M. Guacci, J. A. Anderson, K. L. Pally, D. Bortis, J. W. Kolar, M. J. Kasper, J. Sanchez, and G. Deboy, "Experimental Characterization of Silicon and Gallium Nitride 200V Power Semiconductors for Modular/Multi-Level Converters Using Advanced Measurement Techniques," IEEE Journal of Emerging and Selected Topics in Power Electronics, pp. 1-1, 2019.

[30] W. Meng, F. Zhang, and Z. Fu, "A high power density inverter design based on GaN power devices," 2018 8th International Conference on Power and Energy Systems, ICPES 2018, pp. 1-5, 2019.

[31] B. Sun, N. E. Iversen, Z. Zhang, and M. A. Andersen, "Research of Gap Filler Material in the GaN Transistor Thermal Management," ICPE 2019 - ECCE Asia - 10th International Conference on Power Electronics - ECCE Asia, pp. 390-395, 2019.

[32] E. A. Jones, M. De Rooij, and S. Biswas, "Gan based DC-DC converter for $48 \mathrm{v}$ automotive applications," WiPDA Asia 2019 - IEEE Workshop on Wide Bandgap Power Devices and Applications in Asia, 2019.

[33] M. de Rooij, Y. Zhang, D. Reusch, and S. Chandrasekaran, "High performance thermal solution for high power eGaN® FET based power converters," PCIM Europe Conference Proceedings, no. 225809, pp. 944-950, 2018.

[34] C. Zhao, B. Trento, L. Jiang, E. A. Jones, B. Liu, Z. Zhang, D. Costinett, F. F. Wang, L. M. Tolbert, J. F. Jansen, R. Kress, and R. Langley, "Design and Implementation of a GaN-Based, 100-kHz, 102-W/in 3 Single-Phase Inverter," IEEE Journal of Emerging and Selected Topics in Power Electronics, vol. 4, no. 3, pp. 824-840, 2016. 